\title{
Marie-Hélène Boblet (ed.), Chances du roman, charmes du mythe
}

\section{Francesca Forcolin}

\section{(2) OpenEdition}

1 Journals

\section{Edizione digitale}

URL: http://journals.openedition.org/studifrancesi/1677

DOI: 10.4000/studifrancesi. 1677

ISSN: 2421-5856

\section{Editore}

Rosenberg \& Sellier

\section{Edizione cartacea}

Data di pubblicazione: 1 novembre 2014

Paginazione: 653-654

ISSN: 0039-2944

\section{Notizia bibliografica digitale}

Francesca Forcolin, « Marie-Hélène Boblet (ed.), Chances du roman, charmes du mythe », Studi Francesi [Online], 174 (LVIII | III) | 2014, online dal 01 novembre 2014, consultato il 18 septembre 2020. URL http://journals.openedition.org/studifrancesi/1677 ; DOI : https://doi.org/10.4000/studifrancesi.1677

Questo documento è stato generato automaticamente il 18 settembre 2020.

\section{(c) (i) $\odot$}

Studi Francesi è distribuita con Licenza Creative Commons Attribuzione - Non commerciale - Non opere derivate 4.0 Internazionale. 


\title{
Marie-Hélène Boblet (ed.), Chances du roman, charmes du mythe
}

\author{
Francesca Forcolin
}

\section{NOTIZIA}

MARIE-HÉLÈNE BOBLET (ed.), Chances du roman, charmes du mythe, Presses Sorbonne

Nouvelle, Parigi, 2013, pp. 216.

1 All'inizio degli anni Sessanta Mircea Eliade affermava come fosse intrinseco alla condizione umana il bisogno di uscire dal Tempo storico e personale introducendosi in universi estranei, seguendo le peripezie di una "storia" attraverso la lettura di romanzi. Menzionava altresì la stretta parentela tra mito e romanzo: se da una parte quest'ultimo riprende, elucidandoli, i grandi temi e schemi collettivi, d'altra parte, a livello della ricezione, la lettura romanzesca ha una funzione mitologica, poiché, come il mito, fa vivere l'esperienza del viaggio in un mondo altro. Su questa necessità umana e sul fascino che provoca il mito si interrogano i contributi del volume, frutto della giornata di studi che si è tenuta nel novembre 2011 alla Sorbona. In che modo sono riattualizzati i miti dopo gli anni Cinquanta? Come vengono, oggi, immaginati e trasmutati Gorgo ed Euridice, la saga di Edipo e la storia di Gesù, figure come l'orco e l'orso, in una commistione tra credenze cristiane e pagane?

2 La prima sezione, «De la mythobiographie à la mythographie: Claude Louis-Combet, Henry Bauchau», analizza il ricorso al mito e la ripresa dell'immaginario culturale arcaico nell'opera di C. Louis-Combet - una "mitobiografia" come ci viene spiegato nei tre contributi che aprono il volume - e nell'opera di H. Bauchau. Stéphanie BOULARD in Fantasmes du mythe chez Claude Louis-Combet. "Gorgô" ou la transposition de la terreur (pp. 13-26) riprende il lato fantastico e gotico di Gorgô (2011), comparabile alla figura di Medusa: un intreccio tra sublime e trasgressione. Mito e animalità è invece il tema di Miroir de Léda che ispira Alain ROMESTAING nel contributo "Miroir de Léda" de Claude LouisCombet: usages mythobiographiques de l'animalité (pp. 27-36). La figura di Medusa, che 
nutre profondamente gli immaginari letterari, ritorna con l'analisi di Le roman de Mélusine e di Gorgô da parte di Cécile CROCE in Les corps de Méduse (pp. 37-44). Gli ultimi due contributi della sezione si affacciano invece sulla scrittura dell'autore belga $\mathrm{H}$. Bauchau e sulla ripresa del mito non come ripetizione del passato, bensì interazione tra memoria collettiva e autoriale. Ne discutono Marie-Camille TOMASI in Henry Bauchau, vers une poétique de la variation. De Jacob à Thésée: parcours d'un imaginaire 'en violence' (pp. 45-53), riprendendo il motivo della lotta iniziatica nei combattimenti di Giacobbe e Teseo, e Myriam WATTHEE-DELMOTTE e Jérémy LAMBERT in Henry Bauchau, écrivain mythographe: enjeux littéraires et ethos auctorial (pp. 55-66).

3 La seconda parte, "Le mythe à l'épreuve du roman: défigurations, refigurations", privilegia quei romanzi dove fanno capolino frammenti trasfigurati dei miti, rimandi a figure ancestrali in una rivisitazione talvolta ludica e ironica del passato. Ne è esempio la ripresa del mito dell'orco nell'opera di M. Tournier, in particolare in Le roi des Aulnes, come ci dice Arlette Bouloumié in Le renouvellement du mythe de l'ogre et ses variantes dans l'œuvre de Michel Tournier (pp. 70-79), e nell'opera di J. Chessex, dove l'orco simboleggia il Caos primordiale (Otilia Carmen coJAN, De Cronos à Dionysos. Présence et usage de la figure de l'ogre dans le roman de Jacques Chessex, pp. 81-89). Alain SCHAFFNER in 'Le puzzle du mythe'. Mélusine dans "Les Fruits du Congo" (pp. 91-102) esamina l'evoluzione della figura leggendaria medievale di Melusina, metà fata metà serpente, così come ci viene presentata da Alexandre Vialatte. E ancora, l'Euridice letta da I. Calvino, unico autore non francofono della raccolta (Delphine GACHET, 'L'altra Euridice' d'Italo Calvino: entre réécriture et réinvention du mythe d'Orphée et Eurydice, pp. 103-112).

Il mito che nutre il romanzo è il tema della successiva sezione "Le roman à l'épreuve du mythe: délinéarisation et remotivation du récit". Frammenti e allusioni al corpus greco-romano, al tema del Graal, al Faust sono insiti nell'opera di G. Perec, studiata da Isabelle DANGY in Présences du mythe dans "La Vie mode d'emploi" de Georges Perec (pp. 115-123). Un'analisi comparatistica delle opere di M. Butor, H. Bauchau e T. Viel ci viene presentata da Jacques POIRIER in Dans les labyrinthes du récit: romans minotauréens et romans dédaléens (pp. 125-133). La rielaborazione del racconto cavalleresco e dei temi medievali nei romanzi di I. Calvino e J. Roubaud ci è proposta da Luisa PALAzzo in Mythe chevaleresque et prouesses du langage: Italo Calvino et Jacques à la quête du roman, pp. 135-144. Il mito dell'orso ritorna invece negli anni Novanta nella scrittura di Sylvie Germain (Mythologies ursine et solsticiale dans "Magnus" de Sylvie Germain. Pour narrer l'inénarrable, une mythopoétique de la parole di Lorine BOsT, pp. 145-153).

L'ultima parte è un'analisi comparatistica sulla ripresa di riferimenti culturali cristiani e pagani nei romanzi di alcuni autori come R. Millet e Ph. Le Guillou, di Le Clézio e Y. Thériault («Intertextualités et interculturalité: vers le roman de demain?»). Della figura cristica si riappropria Ph. Le Guillou come ci spiega Jean-François FRACKOWIAK in Écrire dans les blancs de l'imaginaire chrétien: "Douze années dans l'enfance du monde", ou l'évangile apocryphe de Philippe Le Guillou (pp. 157-168). Il mito di Sion è invece rimaneggiato da R. Millet, il quale parte dalla sua storia personale creando quello che Jean-Yves LAURICHESSE definisce un "effetto mito" (Siom dans l'œuvre de Richard Millet ou le deuil du mythe, pp. 169-178). I successivi contributi vertono sull'eredità della cultura oltreoceano in quella del Vecchio Mondo, come si può notare nel romanzo Ourania di Le Clézio (Sols/seuils de la légende et du mythe dans "Ourania" de J.-M. G. Le Clézio di Van KeLLY, pp. 179-187). Gioco di forze tra le tradizioni primitive e il mondo moderno è centrale nella scrittura di $Y$. Thériault, analizzata da Marie-Elaine BOURGEOIs in La figure du Trickster chez Yves 
Thériault: quand le mythe décrie une réalité, pp. 189-197. Chiude il volume il contributo di Jean-Pierre тномаS, Sylvain Trudel, la genèse d'une mythologie? (pp. 199-207), analisi del rinnovamento dei modelli tradizionali nell'opera dello scrittore canadese S. Trudel: una sorta di summa dei motivi che ritornano in questi atti del convegno parigino, dalla rimessa in gioco moderna di motivi ancestrali, alla seduzione dell'intertestualità, all'ispirazione data dalla ricchezza poetica dei miti. 